\title{
Removal of Some Pharmaceuticals and Endocrine Disrupting Compounds by The Marine Macro- algae Pterocladia capillacea and Ulva lactuca
}

\author{
Soad M. Mohy El-Din", Nadia H. Noaman and Seham H. Zaki \\ Botany and Microbiology Department, Faculty of science, \\ Alexandria University, Egypt.
}

\begin{abstract}
D HYTOREMEDIATION of waters by aquatic organisms such as algae has been recently explored for the removal of organic pollutants possessing endocrine disrupting capacity. Two marines macro-algae Pterocladia capillacea and Ulva lactuca were tested for removal of chloramphenicol, clofibric acid, acetyl salicylic acid, nonylphenol and bisphenol in aqueous solutions at concentrations 5$60 \mathrm{mg} / \mathrm{L}$ under controlled laboratory conditions. The obtained results showed that chlorophyll "a" content of both algal biomasses reduced with increasing pharmaceuticals concentrations. Chlorophyll "a "content was diminished nearly to the half at concentration $45 \mathrm{mg} / \mathrm{L}$ for both algal species. However, the nonylphenol and bisphenol were showed a strong inhibition of chlorophyll "a" biosynthesis at higher concentrations (50-60 $\mathrm{mg} / \mathrm{L}$ ). Both the Pterocladia capillacea and Ulva lactuca recorded the highest removal percentage of pharmaceuticals occurred at 12 hours of contact. Pterocladia capillacea had high capacity for bioremoval of pharmaceuticals and endocrine disruptor compounds than Ulva lactuca. The results also revealed that Pterocladia capillacea was recorded the maximum biosorption of pharmaceuticals and endocrine disruptor compounds in order nonylphenol > acetyl salicylic acid > clofibric acid > bisphenol > chloramphenicol, while the maximum biosorption exhibited by Ulva lactuca was recorded in order acetyl salicylic acid $>$ clofibric acid > bisphenol > nonylphenol > chloramphenicol at contact time 12 hours. Both the tested algae suffered from oxidative stress as a result of pharmaceuticals and endocrine disruptor compounds exposure. Our results showed elevation in the antioxidant enzymes superoxide dismutase (SOD), ascorbate peroxidase (APO), catalase (CAT) levels in the tested algae after exposure to different pharmaceuticals when compared with their activities in the control.
\end{abstract}

Keywords: Macro-algae, Pharmaceuticals, Biosorption, Antioxidant enzymes.

Over the last few years, increasing human population and industrial development has led to an their active metabolites may enter the aquatic environment via septic systems, spray irrigation of treated wastewater, leachates from disposal sites, wastewater from sewage treatment plants and the use of sludge's in agriculture (Henschel et al., 1997). Personal care product pollutants have become an emerging area

*Corresponding Author: E-mail: dr.soad_mohi@hotmail.com 
of concern in the field of ecotoxicology, causing them to be viewed as a new class of priority pollutants (Zuccato et al., 2000). Because of the persistence of many personal care products in the environment, there may be potential for these chemicals to negatively affect aquatic organisms. Pharmaceuticals are designed to have a biological effect and therefore these substances may cause similar effects in non-target organisms (Henschel et al., 1997). The removal of this compound from aqueous environments or its reduction to non-toxic levels is a priority goal in water quality management (Gattullo et al., 2012).

Algae are sensitive indicators of environmental change and, as the basis of most freshwater and marine ecosystems, are widely used in the assessment of risk and development of environmental regulations for (Levy et al.2007). There are a remarkable number of investigations demonstrating the toxic effects of Pharmaceuticals on different species of algae (Gattullo et al., 2012).

As primary producers and at the base of aquatic food chains, algae play an important role of maintaining the balance of the aquatic ecosystem. Many reports have indicated that algae have the ability to accumulate and concentrate pollutants such as heavy metals, hexachlorobenzene, herbicides, insecticides and phenol, the pollutants can enter aquatic food chains through algal bioaccumulation (Jonsson et al.,2001 Shin et al., 2002 and Newsted, 2004). The biodegradation of environmental contaminants by algae has also reported (Yang et al., 2002).

Among decontamination techniques, algae used in the removal of organic compounds is one of the best accepted by scientists, governmental authorities and the public because of its ecological and economical sustainability. This emerging technology, which exploits plants to uptake, degrade, stabilize or volatilize toxic compounds present in different media (Loffredo et al .,2010). In recent years, phytoremediation of waters by using phototrophic aquatic organisms such as algae instead of plants proved to be successful for the removal of both organic and inorganic pollutants (Dosnon-Olette et al., 2010). In particular, positive outcomes were obtained by using green algae and marine diatoms for the remediation of simple aqueous system from bisphenol ( $\mathrm{Li}$ et al. 2009 and Gattullo et al., 2012).

Specific marine macroalgae abundant at the Protuguese coast (Laminaria hyperborean, Bilurcaria bifurcate, Sargassum muticum, Gracilaria domingensis and Fucus spiralis) were shown to be effective for removing inorganic pollutants from aqueous media (Freitas et al.2008 and Bouzon et al., 2012).

This investigation was focused on the capacity of Pterocladia capillacea and Ulva lactuca for the removal of pharmaceuticals and endocrine disruptor compounds. To this end, we measured changes in antioxidant enzymatic activities of tested algae in response to chloramphenicol, clofibric, acetyl salicylic acid, nonylphenol and bisphenol stress.

Egypt. J. Bot., 57, No. 1 (2017) 


\section{Materials and Methods}

\section{Test algae}

Pterocladia capillace (c. Agardh) is a genus of red macro-algae, class Florideophyceae and order Gelidiales. Ulva lactuca linneals (Gmel) Born is a genus of green macro-algae, class Ulvophyceae and order Ulvales. Healthy samples of the algae were collected from about one and half meter depth of Mediterranean Sea shore of Alexandria, Abu-Qir in 2014

\section{Chemicals}

All chemicals reagents employed in this study were purchased from sigma Aldrich, companies (Table 1). The concentrations of pharmaceutical were quantified using HPLC device equipped with UV-light spectrophotometer or fluorescence detector. The instrument was initially calibrated before each use with standard solution for each compound. Conditions of HPLC assay for acetyl salicylic acid by (Akay et al., 2008), chloramphenicol by (Barata et al., 2005), clofibric acid by (Lau-Cam et al., 2006), nonylphenol by (Wang and Xie, 2007) and bisphenol by (Gattullo et al., 2012).

TABLE 1. The chemical structure and IUPAC name of different pharmaceuticals used in this study.

\begin{tabular}{|l|l|l|}
\hline $\begin{array}{l}\text { Pharmaceutical } \\
\text { name }\end{array}$ & $\begin{array}{c}\text { International union of pure and } \\
\text { applied chemistry (IUPAC) Name }\end{array}$ \\
\hline $\begin{array}{l}\text { Acetyl salicylic } \\
\text { acid }\end{array}$ & $\begin{array}{c}\text { 2,2-dichloro-N-[1,3-dihydroxy-1- } \\
\text { (4nitrophenyl)propan-2-yl] } \\
\text { acetamide }\end{array}$ \\
\hline Nonylphenol & 2-acetoxybenzoic acid \\
\hline Bisphenol & $\begin{array}{c}\text { 2-(4-Chlorophenoxy)-2- } \\
\text { methylpropanoic acid }\end{array}$ \\
\hline 4-(2,4-dimethylheptan-3yl)phenol
\end{tabular}

Preparation of pharmaceutical and endocrine disruptors solutions

The stocks of acetyl salicylic acid, clofibric acid, nonylphenol and bisphenol were prepared by dissolving 1000mg of each pharmaceutical compound in one liter 
of methanol while for chloramphenicol was prepared by dissolving $1000 \mathrm{mg}$ of antibiotic in one liter of deionized distilled water.

\section{Experimental design}

Pterocladia capillacea and Ulva lactuca were grown in 500 Erlenmeyer flasks by mixing $1 \mathrm{gm}$ of fresh algal biomass with $100 \mathrm{ml}$ of pharmaceutical solution of specific concentration. The different concentrations of pharmaceuticals were prepared viz, $5,10,15,20,25,30,35$ and $60 \mathrm{mg} / \mathrm{L}$ were used in experiments. The compound concentration prepared by adequate dilution of its stock solution using seawater. The mixture was agitated for desired time, then algal materials were filtered through filter paper and final concentration of the compound was determined by HPLC device equipped with UV visible spectrophotometer. This experiment was performed at natural light photoperiod (16h. light/8h. dark) and room temperature $\left(29 \pm 2{ }^{\circ} \mathrm{C}\right)$ with three replicas. The control was carried out by using the algal biomass in seawater (without addition of pharmaceutical compounds). The biosorption experiment concentrations of acetyl salicylic acid $(20 \mathrm{mg} / \mathrm{L}$ for Pterocladia capillacea and $20 \mathrm{mg} / \mathrm{L}$ for Ulva lactuca), chloramphenicol $(25 \mathrm{mg} / \mathrm{L}$ for Pterocladia capillacea and $15 \mathrm{mg} / \mathrm{L}$ for Ulva lactuca), clofibric acid $(5 \mathrm{mg} / \mathrm{L}$ for Pterocladia capillacea and $35 \mathrm{mg} / \mathrm{L}$ for Ulva lactuca), nonylphenol $(5 \mathrm{mg} / \mathrm{L}$ for Pterocladia capillacea and $20 \mathrm{mg} / \mathrm{L}$ for Ulva lactuca ) and bisphenol (10 $\mathrm{mg} / \mathrm{L}$ for Pterocladia capillacea and $20 \mathrm{mg} / \mathrm{L}$ for Ulva lactuca).

The amount of compound adsorbed by alga at equilibrium, $\mathrm{q}(\mathrm{mg} / \mathrm{g})$, which represent the compound uptake was calculated from the difference in compound concentration in the aqueous phase before and after sorption according to the following equation ( Hashim \& Chu, 2004 and Basha et al., 2008):

Compound uptake $=(\mathrm{Ci}-\mathrm{Cf} / \mathrm{W}) \times \mathrm{V}$

Where $\mathrm{V}$ is the volume of compound solution, $\mathrm{Ci}$ and $\mathrm{Cf}$ are the initial and final concentration of compound in solution $(\mathrm{mg} / \mathrm{l})$, respectively and $\mathrm{W}$ is the mass of fresh alga ( $\mathrm{g})$. (Ci - Cf) represented the concentration of compound sorbet by algae at equilibrium, $(\mathrm{mg} / \mathrm{l})$. The removal percentage of the compound by studied alga was estimated from the following equation:

$$
\text { Biosorption }(\%)=(\mathrm{Ci}-\mathrm{Cf} / \mathrm{Ci}) \times 100
$$

Estimation of chlorophyll " $a$ "

The amount of chlorophyll "a" present in the algae was estimated by the method of Arnon (1949) $500 \mathrm{mg}$ of fresh algal tissue was kept in a pestle and mortar with $10 \mathrm{ml}$ of acetone and it was ground well, and the homogenate was centrifuged at $3000 \mathrm{rpm}$ for $15 \mathrm{~min}$. Absorbance was measured at $645 \mathrm{~nm}$ and $663 \mathrm{~nm}$. The chlorophyll content was determined by using the following formula.

$$
\text { Chlorophyll "a"(mg/g fr. wt. })=\frac{12.7 \times A 663-2.69 \times A 645}{a \times 1000 \times W} \times \mathrm{V}
$$

Where, $\mathrm{A}=$ Absorbance at respective wave length, $\mathrm{V}=$ volume of extract $(\mathrm{ml}), \mathrm{W}=$ Fresh weight of sample.

Egypt. J. Bot., 57, No. 1 (2017) 
Biochemical analyses

Superoxide dismutase (SOD), ascorbate peroxidase (APO), catalase (CAT) and protein content was assessed in the samples.

The samples of the control and of the pharmaceuticals treatment of Pterocladia capillacea and Ulva lactuca were homogenized in $20 \mathrm{Mm}$ phosphate buffer, Ph7.4 and centrifuged at $1000 \mathrm{~g}$ for $10 \mathrm{~min}$ at $4^{\circ} \mathrm{C}$. The supernatant was separated and used for assessing superoxide dismutase (SOD), ascorbate peroxidase (APO), catalase (CAT) and protein content.

Superoxide dismutase (SOD) assay

Total SOD activity was determined by measuring its ability to inhibit the photochemical reduction of nitro blue tetrazolium chloride (NBT), as described by (Giannopolitis and Ries, 1977).

Ascorbate peroxidase (APO) assay

Total APO activity was assayed according to Nakano and Asada (1981).

Catalase (CAT) assay

Total CAT activity was measured according the method of Beer and Sizer (1952),

\section{Protein determination}

Protein was determined by the method described by Hartree (1972) which is modification of original method of Lowery (1951). The intensity of blue color developed was measured using spectrophotometer at $650 \mathrm{~nm}$.

\section{Statistical analyses}

Statistical analysis employed SPSS version 10.0 for testing significance of differences between treatments and control at the 0.05 probability level $(\mathrm{P}=0.05)$. Most of experiments were tested with analysis of variance F test (ANOVA) and some of them were tested with Student's t test.

\section{Results}

Effect of pharmaceutical concentrations on chlorophyll a content

Experiments were carried out to choose the appropriate range of pharmaceuticals concentrations. The effect of different concentrations of chloramphenicol, clofibric acid, acetyl salicylic acid, nonylphenol and bisphenol on the chlorophyll a content of both tested algae was shown in Fig 1 and 2, which demonstrated that chlorophyll "a" content of both algal biomasses reduced with increasing pharmaceuticals concentrations. Chlorophyll "a "content was diminished nearly to half at $45 \mathrm{mg} / \mathrm{l}$ for both algal species. However, the nonylphenol and bisphenol were showed a strong inhibition of chlorophyll "a" biosynthesis at higher concentration s $(50-60 \mathrm{mg} / \mathrm{l})$. This effect seemly to be more pronounced in Pterocladia capillacea followed by Ulva 
lactuca. The values of chlorophyll "a" were significantly different for the control and different pharmaceuticals treated algae.

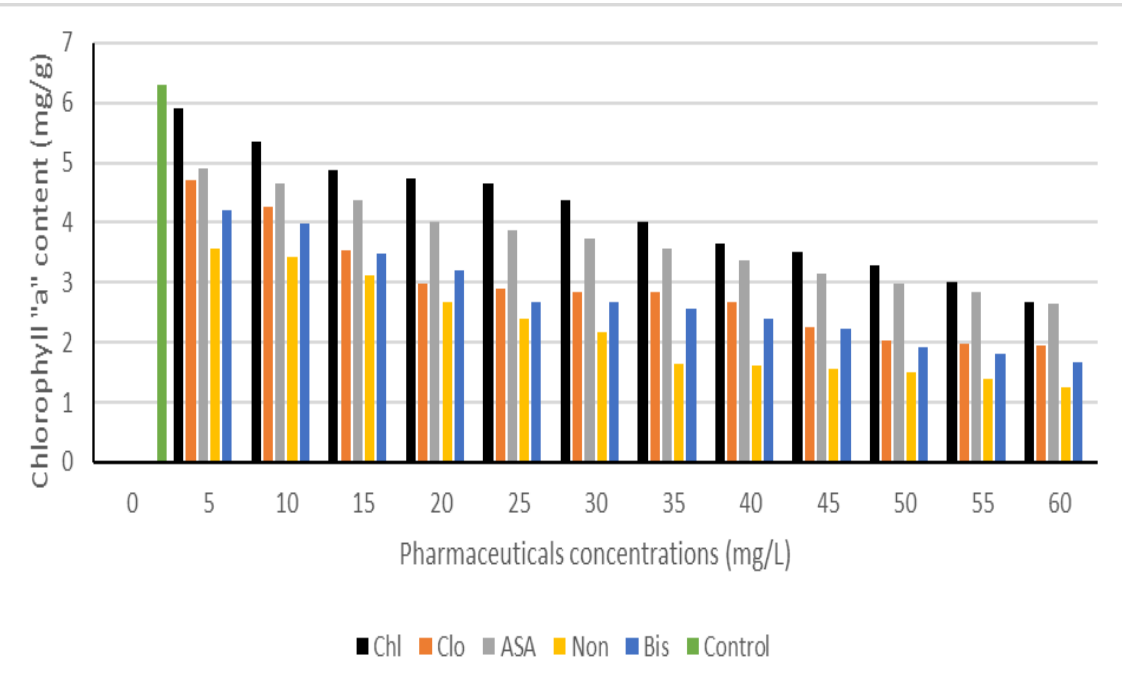

Fig. 1. Effect of different concentrations of pharmaceuticals and endocrine disruptor compounds on chlorophyll "a" content of Pterocladia capillacea. (mean and standard deviation of three replicates are shown)

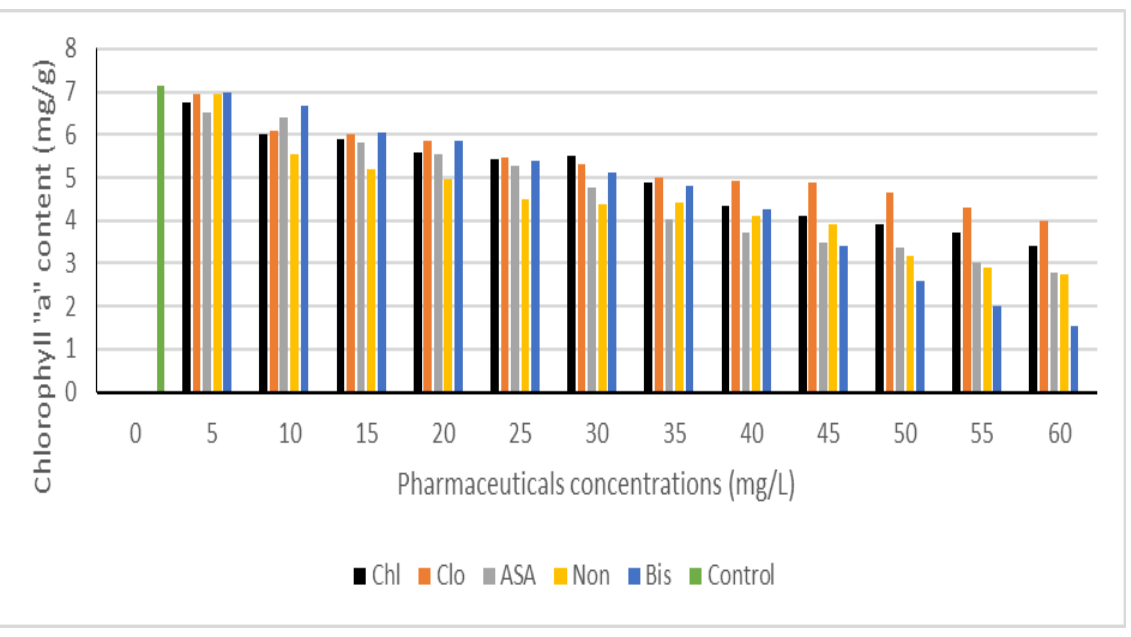

Fig. 2. Effect of different concentrations of pharmaceuticals and endocrine disruptor compounds on chlorophyll "a" content of Ulva lactuca (mean and standard deviation of three replicates are shown)

\section{The pharmaceuticals biosorption}

Biosorption has always been reported as a promising method to treat various kinds of pollutants. Table 2 and 3 showed the biosorption of pharmaceuticals and Egypt. J. Bot., 57, No. 1 (2017) 
endocrine disruptor compounds (chloramphenicol, clofibric acid, acetyl salicylic acid, nonylphenol and bisphenol) by red macro-alga Pterocladia capillacea and green macro-alga Ulva lactuca. The obtained results showed that Pterocladia capillacea had high capacity for bioremoval of pharmaceuticals and endocrine disruptor compounds than Ulva lactuca. On the other hand, both the tested algae had high capacity for bioremoval of pharmaceuticals and endocrine disruptor compounds. Pterocladia capillacea was recorded the maximum biosorption of pharmaceuticals and endocrine disruptor compounds in order nonylphenol > acetyl salicylic acid > clofibric acid > bisphenol > chloramphenicol, while the maximum biosorption exhibited by Ulva lactuca was recorded in order acetyl salicylic acid $>$ clofibric acid > bisphenol > nonylphenol > chloramphenicol at contact time 12 hr. The tolerant of both macro-algae, showed a high efficiency of pharmaceuticals and endocrine disruptor compounds biosorption. It can be observed that the removal percentage of all pharmaceuticals increase with the increase in contact time up to $12 \mathrm{hr}$ as Tables 2 and 3. It can be also noticed that removal percentage of both algal fresh biomasses varied significantly with elevation of contact time. The maximum removal of pharmaceuticals occurred during $12 \mathrm{hr}$ of contact recording $100 \%$ nonylphenol, $98.25 \%$ for acetyl salicylic acid, $97.72 \%$ for clofibric acid, 97.12 for bisphenol and $89.34 \%$ for chloramphenicol by Pterocladia capillacea, while the maximum removal of pharmaceuticals was recorded $98.39 \%$ for acetyl salicylic acid, $97.05 \%$ for clofibric acid, $96.90 \%$ for bisphenol, $95.10 \%$ for nonylphenol and $90.80 \%$ for chloramphenicol by Ulva lactuca. By increasing the exposure time to $24 \mathrm{hr}$, the removal percentage of all pharmaceuticals decreased, except the removal percentage nonylphenol stay unchanged during $24 \mathrm{hr}$ of contact in Pterocladia capillacea,. The maximum biosorption was achieved by both algae after $12 \mathrm{hr}$. Moreover, increasing contact time from 12 up to 36 hours resulted in a slight decrease in biosorption of all pharmaceuticals.

TABLE 2. Uptake capacity (mg/g) and biosorption (\%) of Pterocladia capillacea for pharmaceuticals and endocrine disruptor compounds at different times. (mean and standard deviation of three replicates are shown)

\begin{tabular}{|c|c|c|c|c|c|c|c|c|c|c|}
\hline \multirow{4}{*}{ T } & \multicolumn{8}{|c|}{ Pharmaceuticals and endocrine disruptor compounds } \\
\cline { 2 - 12 } & Chloramphenicol & \multicolumn{2}{c|}{ Clofibric acid } & Acetyl salicylic & Nonylphenol & \multicolumn{2}{|c|}{ Bisphenol } \\
\cline { 2 - 12 } & $\mathbf{U C}$ & $\mathbf{B}$ & $\mathbf{U C}$ & $\mathbf{B}$ & $\mathbf{U C}$ & $\mathbf{B}$ & $\mathbf{U C}$ & $\mathbf{B}$ & $\mathbf{U C}$ & $\mathbf{B}$ \\
\hline 0 & 0.00 & 0.00 & 0.00 & 0.00 & 0.00 & 0.00 & 0.00 & 0.00 & 0.00 & 0.00 \\
\hline \multirow{2}{*}{2} & $18.65 \pm 0$ & $74.61 \pm$ & $4.71 \pm$ & $92.00 \pm$ & $14.70 \pm$ & $97.94 \pm$ & $3.95 \pm$ & $79.01 \pm$ & $9.49 \pm$ & $94.49 \pm$ \\
& .02 & 0.03 & 0.022 & 0.01 & 0.003 & 0.002 & 0.01 & 0.003 & 0.02 & 0.002 \\
\hline \multirow{2}{*}{4} & $18.79 \pm 0$ & $75.16 \pm$ & $4.73 \pm$ & $93.00 \pm$ & $14.80 \pm$ & $97.96 \pm$ & $4.17 \pm$ & $83.37 \pm$ & $9.51 \pm$ & $95.07 \pm$ \\
& .011 & 0.021 & 0.011 & 0.01 & 0.01 & 0.01 & 0.012 & 0.021 & 0.001 & 0.12 \\
\hline \multirow{2}{*}{6} & $19.09 \pm 0$ & $76.35 \pm$ & $4.76 \pm$ & $94.18 \pm$ & $14.70 \pm$ & $98.02 \pm$ & $4.36 \pm$ & $87.15 \pm$ & $9.53 \pm$ & $95.27 \pm$ \\
& .022 & 0.012 & 0.02 & 0.011 & 0.002 & 0.002 & 0.12 & 0.002 & 0.01 & 0.021 \\
\hline & $20.47 \pm 0$ & $81.87 \pm$ & $4.76 \pm$ & $95.24 \pm$ & $14.70 \pm$ & $98.01 \pm$ & $4.67 \pm$ & $93.38 \pm$ & $9.64 \pm$ & $96.40 \pm$ \\
& .02 & 0.02 & 0.01 & 0.002 & 0.02 & 0.001 & 0.02 & 0.002 & 0.001 & 0.011 \\
\hline 1 & $21.69 \pm 0$ & $86.74 \pm$ & $4.78 \pm$ & $95.53 \pm$ & $14.70 \pm$ & $98.03 \pm$ & $4.75 \pm$ & $95.01 \pm$ & $9.70 \pm$ & $96.99 \pm$ \\
0 & .01 & 0.01 & 0.03 & 0.02 & 0.1 & 0.002 & 0.022 & 0.001 & 0.024 & 0.01 \\
\hline 1 & $22.34 \pm 0$ & $89.34 \pm$ & $4.89 \pm$ & $97.72 \pm$ & $14.73 \pm$ & $98.25 \pm$ & $5.00 \pm$ & $100 \pm 0$. & $9.71 \pm$ & $97.12 \pm$ \\
2 & .01 & 0.01 & 0.02 & 0.03 & 0.002 & 0.011 & 0.003 & 01 & 0.021 & 0.02 \\
\hline 2 & $22.19 \pm 0$ & $88.77 \pm$ & $4.77 \pm$ & $95.31 \pm$ & $14.71 \pm$ & $98.05 \pm$ & $5.00 \pm$ & $100 \pm 0$. & $9.66 \pm$ & $96.60 \pm$ \\
4 & .01 & 0.02 & 0.02 & 0.022 & 0.003 & 0.021 & 0.011 & 01 & 0.001 & 0.012 \\
\hline
\end{tabular}

T: mean Time (hours) UC: mean Uptake capacity $(\mathrm{mg} / \mathrm{g})$

B: mean Biosorption (\%) 
TABLE 3. Uptake capacity (mg/g) and Biosorption (\%) of Ulva lactuca for pharmaceuticals and endocrine disruptor compounds at different times.(mean and standard deviation of three replicates are shown)

\begin{tabular}{|c|c|c|c|c|c|c|c|c|c|c|}
\hline \multirow{3}{*}{$\mathrm{T}$} & \multicolumn{8}{|c|}{ Pharmaceuticals and endocrine disruptor compounds } \\
\cline { 2 - 11 } & \multicolumn{1}{|c|}{ Chloramphenicol } & \multicolumn{2}{c|}{ Clofibric acid } & \multicolumn{2}{|c|}{ Acetyl salicylic } & \multicolumn{2}{|c|}{ Nonylphenol } & \multicolumn{2}{c|}{ Bisphenol } \\
\cline { 2 - 12 } & UC & B & UC & B & UC & B & UC & B & UC & B \\
\hline 0 & 0.00 & 0.00 & 0.00 & 0.00 & 0.00 & 0.00 & 0.00 & 0.00 & 0.00 & 0.00 \\
\hline \multirow{2}{*}{2} & $7.19 \pm 0$ & 47.93 & 32.14 & 91.82 & 19.03 & 95.15 & $14.65 \pm$ & $73.26 \pm$ & $18.11 \pm$ & 90.53 \\
& .01 & \pm 0.03 & \pm 0.02 & \pm 0.02 & \pm 0.02 & \pm 0.01 & 0.02 & 0.021 & 0.1 & \pm 0.22 \\
\hline \multirow{2}{*}{4} & $8.30 \pm 0$ & 55.32 & 32.71 & 92.00 & 19.17 & 95.85 & $15.88 \pm$ & $79.38 \pm$ & $18.77 \pm$ & 93.84 \\
& .02 & \pm 0.04 & \pm 0.02 & \pm 0.02 & \pm 0.02 & \pm 0.01 & 0.02 & 0.02 & 0.02 & \pm 0.01 \\
\hline \multirow{2}{*}{6} & $9.47 \pm 0$ & 63.12 & 32.73 & 93.51 & 19.28 & 96.38 & $16.48 \pm$ & $82.39 \pm$ & $18.93 \pm$ & 94.64 \\
& .01 & \pm 0.01 & \pm 0.1 & \pm 0.01 & \pm 0.01 & \pm 0.02 & 0.01 & 0.01 & 0.001 & \pm 0.02 \\
\hline \multirow{2}{*}{8} & $10.72 \pm$ & 71.46 & 33.16 & 94.73 & 19.49 & 97.42 & $17.69 \pm$ & $88.41 \pm$ & $19.19 \pm$ & 95.97 \\
& 0.01 & \pm 0.02 & \pm 0.02 & \pm 0.01 & \pm 0.01 & \pm 0.01 & 0.02 & 0.01 & 0.01 & \pm 0.01 \\
\hline \multirow{2}{*}{10} & $11.89 \pm$ & 79.26 & 33.27 & 95.04 & 19.59 & 97.99 & $18.58 \pm$ & $92.87 \pm$ & $19.32 \pm$ & 96.58 \\
& 0.02 & \pm 0.02 & \pm 0.06 & \pm 0.3 & \pm 0.01 & \pm 0.01 & 0.06 & 0.01 & 0.05 & \pm 0.01 \\
\hline \multirow{2}{*}{12} & $13.08 \pm$ & 90.80 & 33.97 & 97.05 & 19.68 & 98.39 & $19.02 \pm$ & $95.10 \pm$ & $19.38 \pm$ & 96.90 \\
& 0.01 & \pm 0.02 & \pm 0.02 & \pm 0.01 & \pm 0.02 & \pm 0.02 & 0.001 & 0.02 & 0.03 & \pm 0.02 \\
\hline \multirow{2}{*}{24} & $13.27 \pm$ & 88.51 & 31.07 & 88.76 & 19.61 & 98.05 & $18.86 \pm$ & $94.31 \pm$ & $19.36 \pm$ & 96.80 \\
& 0.03 & \pm 0.01 & \pm 0.1 & \pm 0.01 & \pm 0.04 & \pm 0.21 & 0.02 & 0.01 & 0.02 & \pm 0.01 \\
\hline
\end{tabular}

$\mathrm{T}$ : mean Time (hours)

UC: mean Uptake capacity $(\mathrm{mg} / \mathrm{g})$

B: mean Biosorption $(\%)$

\section{Effect of different pharmaceuticals on protein content}

Protein accumulations in cell of Pterocladia capillacea and Ulva lactuca were weakly influenced by the treatment with different pharmaceuticals. The data in Fig. 3 indicate the increase of protein content of Pterocladia capillacea significantly by $6.38,4.07,3.61$ and $2.13 \%$ on using chloramphenicol, acetyl salicylic acid, clofibric acid and nonylphenol respectively as compared to control, . While total protein content of Ulva lactuca significantly elevated by 7.47, 2.65, 25 and $17.5 \%$ comparable to control after treatment with chloramphenicol, acetyl salicylic acid, clofibric acid and nonylphenol respectively. It must be mentioned that the highest protein content was recorded in the chloramphenicol and clofibric acid of Pterocladia capillacea and Ulva lactuca respectively.

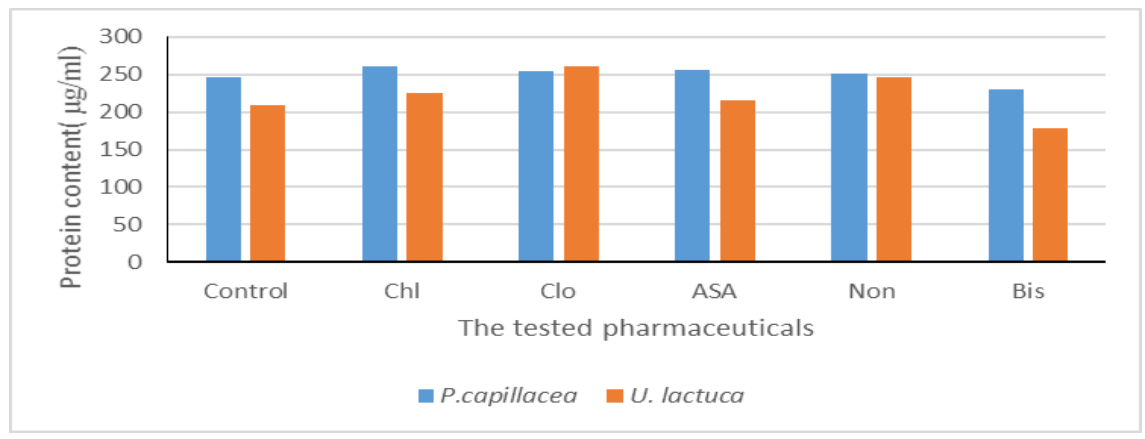

Fig. 3. Effect of pharmaceuticals and endocrine disruptor compounds on protein content of Pterocladia capillacea and Ulva lactuca. (mean and standard deviation of three replicates are shown)

Egypt. J. Bot., 57, No. 1 (2017) 
REMOVAL OF SOME PHARMACEUTICALS AND ENDOCRINE DISRUPTING 147

\section{Biochemical activities}

Enzyme activities of the tested species of algae with various pharmaceuticals exposure are presented in Fig. 4. Results of antioxidant enzymes activity superoxide dismutase (SOD), ascorbate peroxidase (APO), catalase (CAT) revealed similar behaviors in the two algal species under study. The three-antioxidant enzymes showed an increase in their activities after being exposed to each of the tested pharmaceuticals compared to their activity in the control group. The variations in SOD activity were narrow among the different drug treated groups. The lowest significant activation of SOD activity values were 0.7213 and $0.5810(\mu \mathrm{g} / \mathrm{mg}$ fresh weight), respectively demonstrated in Pterocladia capillacea and Ulva lactuca exposed to acetyl salicylic acid compared with control values.

APO enzyme activity values showed remarkable significant elevations in the two algal species under different pharmaceutical treatments. The lowest increase in APO activity compared to control was observed in acetyl salicylic acid for both tested algae. It is worthy noted that APO activity varied significantly with control after treatment with different pharmaceuticals in case Pterocladia capillacea while it showed non-significance in case of Ulva lactuca.

CAT enzyme activity in two algal biomasses exhibited a considerable variable enhancement after exposure to different pharmaceuticals. The most obvious increases in CAT activity values detected by Pterocladia capillacea and Ulva lactuca treated with nonylphenol. They increased significantly by 7.374 and $13.84(\mu \mathrm{g} / \mathrm{mg}$ fresh weight) respectively compared to control.

\section{Discussion}

The toxic effect of the pharmaceuticals chloramphenicol, clofibric, acetyl salicylic acid, nonylphenol and bisphenol were assessed on the macroalgae Pterocladia capillacea and Ulva lactuca, using bioassays to enlarge the ecotoxicological information about the risk of these drugs when they reach the environment. During the present study algae were found to be sensitive to the effects of different pharmaceuticals

Chlorophyll "a" was determined in this study as a biomarker to assess the effect of different concentrations of some pharmaceuticals and endocrine disruptor compounds on algae . The amount of chlorophyll "a" decreased under the various pharmaceuticals stress. The decreases of chlorophyll "a" content accompanied with elevating concentration of acetyl salicylic acid may be the result of toxicity posed by the acid on the pigment content, which might be ascribed to the generation of reactive oxygen species (ROS) under acetyl salicylic acid stress. This explanation agrees with that given by Brain et al. (2004) who described acetaminophen or paracetamol toxicity to growth rate and pigment content of two macrophytes when mixed with other seven pharmaceuticals. 
Drop in chlorophyll "a" content after exposure to different concentrations of chloramphenicol may be due to the inhibition of chlorophyll a synthesis. The pattern of chlorophyll a decrease investigated in this study was in consonance with the results of Kumar et al. (2012), who investigated a reduction in chlorophyll a content of Anabaena fertilissma, Autosira fertilissima and Westiellopsis prolifica cells caused by endosulfan and tebuconazle treatments at various concentrations.

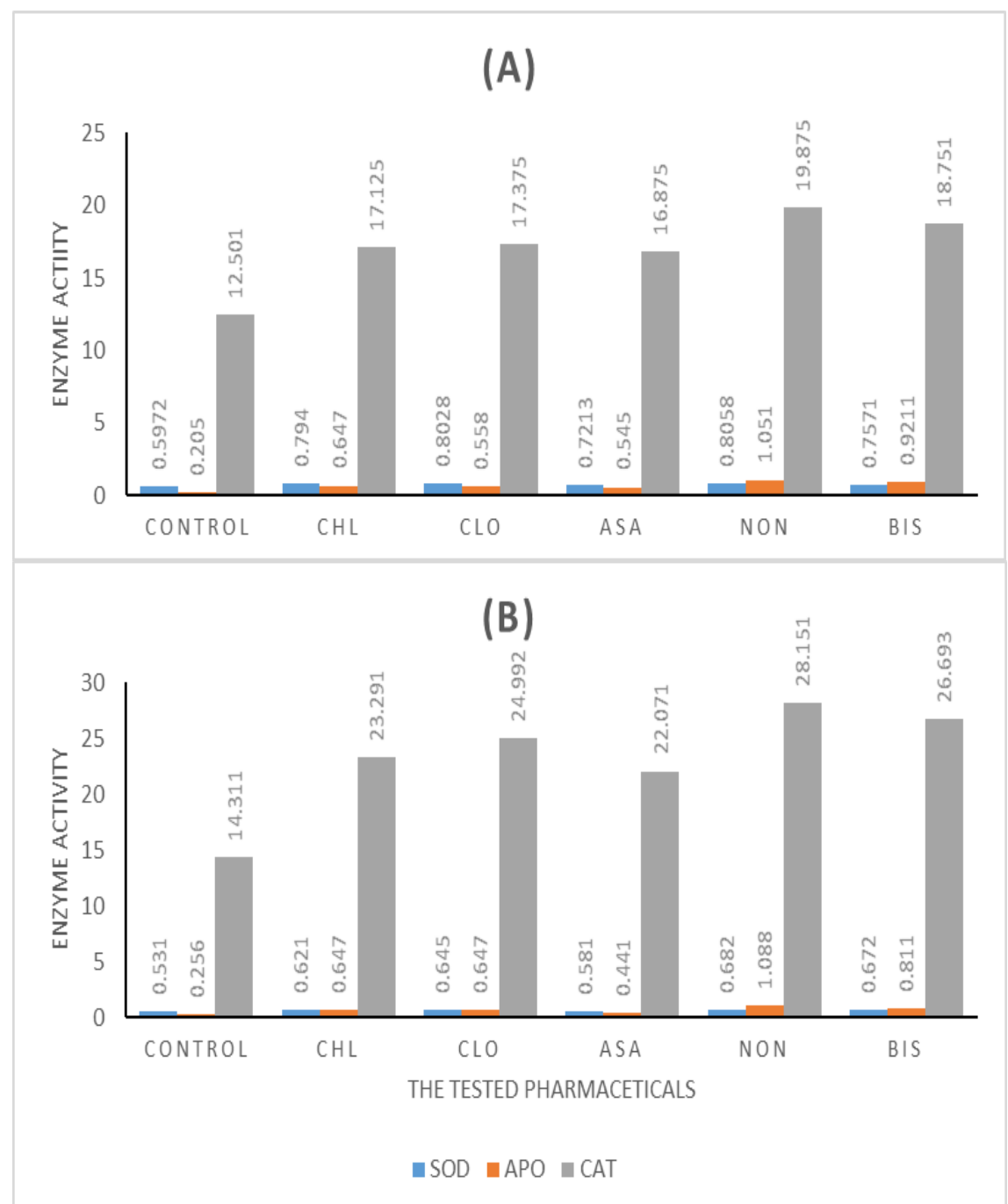

Fig. 4. Effect of pharmaceuticals and endocrine disruptor compounds on the enzyme activities ( $\mu \mathrm{g} / \mathrm{mg}$ fresh weight) of superoxide dismutase (SOD), ascorbate peroxidase (APO), catalase (CAT) of (A) Pterocladia capillacea and (B) Ulva lactuca (mean and standard deviation of three replicates are shown) 
The decline in chlorophyll "a" content of both tested algae as a function of clofibric acid concentration observed in this study is related to the nature of the acid, which was proved to be a promoter of B-oxidation in both mammals and plants. As a consequence, the treatment with clofibric induced the generation of ROS, which in turn damaged the chloroplast membranes. This in agreement with the results of Barros et al.(2003), who detected a significant decrease in photosynthetic activity of PSII of the red alga Kappaphycus alvarezii after addition of clofibric acid to sea water containing the alga.

The disintegration of chloroplast and chlorophyll molecules could be direct causes of chlorophyll "a" content decrease due to nonylphenol and bisphenol stress and these findings are congruent with those obtained by Wang et al. (2007) and Li et al. (2008).

Biosorption efficiency of fresh Pterocladia capillacea and Ulva lactuca for the removal of pharmaceutical by fresh algal biomasses was measured in term of compound uptake and compound removal percentage as a function of different initial pharmaceutical concentration at different time intervals. Increase of uptake of either pharmaceuticals by two algal with elevating initial concentration of the compound could be discussed by the fact that the initial concentration provides an important driving force to overcome all mass transfer resistances of the compound between the aqueous phase and the solid phases. Hence a higher initial concentration of the compound may enhance the process. In addition, increasing the initial compound concentration increases the number of collision between the compound and seaweed enhancing adsorption process. These finding is in consistence with those obtained by Daneshvar et al. (2006) who found that the amount of color removed by Cosmarium sp. Varies with different initial dye concentration and increases with increasing initial dye concentration. Also Chung et al. (2006) demonstrated that the sorption of aqueous phenanthrene onto dead Saragassum tissue was a concentration dependent process and higher initial concentration of sorbet resulted in higher probability of collision between sorbet and adsorbent and increases uptake of phenanthrene. These finding are also supported by many other studies for example, Tamilsevan et al.(2012) who used Sargassum wightii and Caulerpa rasemosa as an adsorbent for removal of $\mathrm{Cr}^{5+}, \mathrm{Cr}^{3+}, \mathrm{Pb}^{2+}$ and $\mathrm{Cd}^{2+}$ ions from aqueous solutions observed an increase in metals uptake with rise in initial metal concentration. Also, in another study conducted by Thirunavkkarasu and Palanivelu (2007) to depict the effect of initial concentration of chromium on the biosorption of metal by the brown alga Padina boergesenli. The authors elucidated that the biosorption of chromium increases with increase chromium concentration.

Contact time is one of the important parameters for successful use of biosorpents for practical application and rapid sorption is among desirable parameters (Yoonaiwong et al., 2011). After $12 \mathrm{hr}$, the concentration of different tested compounds began to increase in solution, which, means that the two algae cannot tolerate these toxicants more than 12 hours. Under this stress, the algae 
had died and these compounds were subsequently released back into the medium following lysing of the cells or possibly by simple diffusion process. Toxicity of many toxicants are thought to be related to overproduction of ROS including the superoxide radical anion, the hydroxyl radical and the hydrogen peroxide via aerobic metabolism and these ROS may cause severe cellular injury by attacking DNA, protein and polyunsaturated fatty acids (Halliwell, 1987). This condition of oxidative stress promotes cell death in a broad variety of disorders (Melchiorri et al., 1996). This suggest that the death of algal cells exerted under the tested compounds stress through over production of ROS.

The Biosorption efficiency of fresh biomasses algae for the removal of pharmaceuticals was measured at each two hours for the total period of 12 hours to determine the shortest exposure time required for maximum biosorption of the tested compound. The maximum removal percentage and uptake were attained at a contact time $12 \mathrm{hr}$. The fast initial metal biosorption rate was referred to the surface binding and the following slower sorption was attributed to the interior penetrating (Lodi et al., 1998; Chojnacka et al., 2005 and Drora. 2013). The effect of contact time on the biosorption of $\mathrm{Pb}^{2+}$ and $\mathrm{Cd}^{2+}$ onto Ulva aurea biomass was studied by Yoonaiwong et al. (2011), who observed rapid uptake of metal ions occurred within five min and equilibrium was reached in $60 \mathrm{~min}$ for $\mathrm{Pb}^{2+}$ and $90 \mathrm{~min}$ for $\mathrm{Cd}^{2+}$ and remained nearly constant afterward.

The data concerning the cell contents of proteins indicated that the two investigated seaweeds were slightly affected by the different pharmaceuticals. The treatment with different pharmaceuticals was mostly accompanied by stimulation of total protein synthesis. It could be suggested that accumulation of protein after treatments may be one of the ways through which the algae can abolish their toxic effects, or increase respiration leading to the utilization of carbohydrate in favor of protein (Osman et al., 2004). In the same context, two other reports discussed the induction of protein synthesis under toxicants stress, one of which was introduced by Yu et al. (2007) who registered increases in soluble protein content of red alga Gracillaria lemaneiformis at low concentrations of dimethyl phthalate, the author referred such increase to the attempt of the alga to start the self -protection mechanism through increasing the cellular and the amount of functional proteins, thus contributed to the maintenance of the normal algae cell metabolism and the second report presented by Wannigama et al. (2012) who detected a similar stimulation of protein accumulation in Anabaena sp. PCC 7120 under short exposure of abiotic stresses including heavy metal, salinity, UV-B and pesticide stress.

The activities of SOD, CAT and APO in the two seaweeds used in our study varied to different extents following exposure of the algal species to different pharmaceuticals, suggesting that the algal cells were under oxidative stress as a result of exposure to utilized compounds and that these antioxidant enzymes may play important roles in eliminating the excessive reactive oxygen species (ROS). The extent to which SOD, CAT activities increased in response to pharmaceuticals

Egypt. J. Bot., 57, No. 1 (2017) 
stress was less than the increased activity shown by APO, demonstrating that APO contribute more significantly in the elimination of the toxic effect of these compounds than SOD and CAT. Usually, a simultaneous induction response in the activities of SOD, APO and CAT is observed when exposed to pollutants (Dimitrova et al., 1994). For instance, Xiong et al. (2005) reported the stimulation of SOD activity was coupled with growth inhibition in the green alga Scenedesmus obliquus following exposure to cypermethrin, Morelli and Scarano (2004) indicated that the exposure to copper could increase the SOD activity in diatom Phaeodactylum tricorntum.

\section{Reference}

Akay, C., Deglm, I.T., Sayal, A., Aydin, A.O.Y. and Gul, H. (2008) Rapid and simultaneous determination of acetyl salicylic acid, paracetamol, and their degradation products by HPLC in pharmaceutical dosage forms. Turk J. Med. Sci., 38 (2) $167-173$.

Arnon, DI. (1949) Copper enzymes in isolated chloroplast, polyphenol oxidase in Beta vulgarise. Plant physiol. 2: 1-15.

Barata, C.N.J., Varo, I., Riva, M., Arun, S. and Porte, C. (2005) Changes in enzyme activities, fatty acid composition and lipid peroxidation in daphnia magna during the aging process compar. biochem. Physiol. Part. B, 140: 8 1-90.

Basha, S., Murthy, Z.V.P. and Jha, B.(2008) Biosorption of hexavalent chromium by chemically modified seaweeds, Cystoseira indica. Chemical Engineering Journal, 137(3), 480-488.

Barros, M., Granbom, M., Colepicolo, P., and Pedersen, M. (2003) Temporal mismatch between the induction of superoxide dismutase and ascorbate peroxidase correlates with high $\mathrm{H} 2 \mathrm{O} 2$ concentration in seawater from clofibrate- treated red algae Kappaphycus alvrezii. Archives of Biochemistry and Biophysics. 420: 161- 168.

Beers S. and Sizer M. (1952) A spectrophotometric method for measuring the breakdown of hydrogen peroxide by catalase. J. Biol. Chem., 195, 133-140.

Brain, R.A., Johnson, D. J., Richards, S.M., Hanson, M.L. Sanderson, H., Lam, M.W., Young, C., Mabury, S.A., Sibley, P.K. and Solomon, K.R., (2004) Microcosm evaluation of the effects of an eight pharmaceutical mixture to the aquatic macrophytes Lemna gibba and Myriophyllum sibiricum. Aquatic Toxicology, 70, 2340

Bouzon, Z., Santos1, R., Schmidt1, E., Martins, R., Latini, A., Maraschin, M. and Horta, P. (2012) Effects of cadmium on growth, photosynthetic pigments, photosynthetic performance, biochemical parameters and structure of chloroplasts in the Agarophyte Gracilaria domingensis (Rhodophyta, Gracilariales). Amer. J plant Sci. 3, 10771084. 
Chung, M.K., Tsui, M.T.K., Cheunga, K.C., Tam, N.F.Y. and Wong, M.H. (2006) Removal of aqueous phenanthrene by brown seaweed Sargassum hemiphyllum: Sorption-Kinetic and equilibrium studies. Separation and Purification Technology.

Daneshvar, N. M. Ayazloo, M.A.R. Khataee, A. and Pourhassan, M. (2006) Biological decolorization of dye solution containing Malachite Green by microalgae Cosmariu m sp Bioresource Technology.

Dimitrova, M., Tsinova, V. and Velcheva, V. (1994) Combined effect of zinc and lead on the hepatic superoxide dismutase system in crap. Comp. Biochem. Physiol. Part C, 108, 43-46.

Drora, K. (2013) Absorption and adsorption of heavy metals by microalgae. Applied Phycol. and Biotechno. $2^{\text {nd }}$ ed Ltd. 602-611.

Dosnon-Olette R, Trotel-Aziz P, Couderchet $M$ et al (2010) Fungicides and herbicide removal in Scenedesmus cell suspensions. Chemosphere, 79, 117-123

Freitas, O.M., Martins, R.J., Delerue-Matos,C. and Boaventura, R.A. (2008) Removal of $\mathrm{Cd}, \mathrm{Zn}$ and $\mathrm{Pb}$ from aqueous solutions by brown marine macro algae: Kinetic modeling. J. Hazard. Mat., 53, 493-501.

Gattulo, C.E., Bahrs, H., Steinberg, C. and Loffredo, E. (2012) Removal of bisphenol Aby the fresh water green alga Monoraphidium braunii and the role of natural organic matter. Science of the Total Environment, 416, 501-506.

Giannopolitis, C.N. and Ries S.K. (1977) Superoxide dismutases: I. Occurrence in higher plants. Plant Physiol. Feb; 59 (2), 309-314.

Halliwell, BB., (1987) oxidative damage, lipid peroxidation and antioxidant protection in chloroplasts. Chem. Phys, Lipids 44, 327-340.

Hartree, E. F. (1979) A modification of lowery method that gives a linear photometric response. Analyt. Biochem. 48, 422.

Hashim, M.A. and Chu, K.H. (2004) Biosorption of cadmium by brown, green and red seaweeds. Chemical Engineering Journal, 97, 249-255.

Henschel, K.P. Wenzel, A., Diedrich M. and Fliedner, A.(1997) Environmental hazard assessment of pharmaceutical. Reg. Toxicaol Pharm. 25, 220-225.

Kumar, N., Bora, A., Kumar, R. and Amb, M.K. (2012) Differential effects of agricultural pesticides endosulfan and tebuconazole on photosynthetic pigments, metabolism and assimilating enzymes of three heterotrophic, filamentous cyanobacteria. J. Biol. Environ. Sci. 6, 67-75.

Jonsson, C.M., Paraiba, L.C., Mendoza, M.T., Sabater, C. and Carrasco, J.M. (2001) Bioconcentration of the insecticide pyridaphenthion by the green alga Chlorella saccharophila. Chemosphere, 43, 321-325. 
Lau-Cam, C., Theofanopulos, V. and Spireas, S.S. (2006) Simplified HPLC method with spectrophotometric detection for the assay of clofibric acid in rat plasma. Plasma. J. of Liquid Chromatography.18, 3945-3954.

Levy, J.L., J.L. Stauberand and D.F. Jolley, (2007) Sensitivity of marine microalgae to Copper: The effect of biotic factors on Copper adsorption and toxicity. Sci. Total Environ, 387, 141-154.

Li, R., Chen, G-Z, Tam, N.F.Y, Luan ,T-G., Shin, P.K. Cheung, S.S.G. and Liu, Y. (2009) Toxicity of bisphenol A and its bioaccumulation and removal by a marine microalga Stephanodiscus hantzschii. Ecotoxicology and Environmental Safety, $\mathbf{7 2}$, $321-328$

Li, R., Liu, Y., Chen, G., Tam, N.F.Y., Shin, P.K.S., Cheung, S.G., and Luan, T. (2008) Physiological responses of the alga Cyclotella caspia to bisphenol A exposure. Botanica Marina, 51, 30-369.

Lodi A., Solisio C., Converti A. and Del Borghi, M. (1998) Cadmium, zinc, copper, silver and chromium removal from wastewater by Sphaerotilus natans, Bioproc. Eng. 19, 197-203.

Loffredo, E., Gattullo, C., Traveras, A. and Senesi, N. (2010) Potential of various herbaceous species to remove the endocrine disruptor bisphenol a from aqueous media. Chemosphere. 80: 1274-80.

Lowery, O.H., Rosenbroug, N.J. Farr, A.F. and Randall, R.J. (1951) Protein measurement with the folin phenol reagent. J. Biol. Chem., 193, 265-275.

Melchiorri, D., Reiter, R.J., Sewerynek, E.,Hara, M.mChen, L. and Nistic, C. (1996) Paraquat toxicity and oxidative damage. Reduction by melatonin. Biochemical Pharmacology. 51, 1095-1099.

Morelli, E. and Scarano, G. (2004) Copper-induced changes of non-protein thiols and antioxidant enzymes in the marine microalga Phaeodactylum tricornutum. Plant Sci., 167, 289-296.

Nakano, Y. and Asada, K. (1981) Hydrogen peroxide is scavenged by ascorbate specific peroxidase in spinach chloroplasts. Plant and Cell Physiology 22, 867-880.

Newsted, J.L. (2004) Effect of light, temperature, and pH on the accumulation of phenol by Selenastrum capricornutum, a green alga. Ecotoxicol. Environ. Saf., 59, $237-243$.

Osman, M.E.H., El-naggar, A.H. EL-Sheekh, M.M. and El-Mazally, E. (2004). Differential effects of $\mathrm{Co}$ and $\mathrm{Ni}$ on protein metabolism in scenedesmus obliquus \& Nitzschia perminuta. Enviro. Tox. Pharmacol.16, 169-178.

Shin, H.W., Sidharthan, M. and Young, K.S. (2002) Forest fire ash impact on microand macroalgae in the receiving waters of the east coast of South Korea. Mar. Pollut. Bull. 45, 203-209. 
Tamilsevan, N., Saurav, K.and Kannabiran, K. (2012) Biosorption of of $^{\mathrm{Cr}^{5+}}, \mathrm{Cr}^{3+}$, $\mathrm{Pb}^{2+}$ and $\mathrm{Cd}^{2+}$ from aqueous solutions by Sargassum wightii and Caulerpa racemose Algal biomass. J. Ocean Univ. China. 1, 52-58.

Thirunavukkarasu, E. and Palanivlu, K. (2007) Biosorption of Cr from plating effluent using marine algal mass. Indian J of biotech. 6, 359-364.

Wannigama, D.L., Agrawal, C. and Rai, L.C. (2012) A comparative study on proteomic and biochemical alterations in the Anabaena Sp. Pcc7120 under short term exposure of abiotic stresses: Pesticide, Salinity, Heavy metal and UV. J. Biotechnol.Biomater. 2: 6 .

Wang, J., Xie, P., and Guo, N. (2007) Effects of nonylphenol on the growth and microcystin production of Microcystis strains. Environmental Research, 103, 70-78.

Xiong, L, Xie, P., Sheng, X.M. Wu, J. and Xie, L., (2005) Toxicity of cypermethrin on growth, pigments and superoxide dismutase of Scendesmus Sp. Ecotoxicol. Enviro. Safety. 60, 188-192.

Yang, S., Wu, R.S.S. and Kong, Y.C. (2002) Biodegradation and enzymatic responses in the marine diatom Skeletonema costatum upon exposure to 2,4-dichlorophenol. Aquat. Toxicol. 59, 191-200.

Yoonaiwong, W., Kaewsarn, P. and Reanprayoon, P. (2011) Biosorption of lead and cadmium ions by non-living aquatic macrophyte, Sustain. Environ. Res., 21, 369-374.

Yu, J., Yang, C., Yu, R.A., and Guya Fu. G., (2007) Toxic response of dimethyl phthalate to Gracilaria Sp. Electronic J. of Bio. 4, 80-86

Zuccato, E., Calamari, D., Natangelo, M. and Fanelli, R. (2000) Presence of therapeutic drugs in the environment. The Lancelot, 35, 1789-179• .

(Received: 19/10 / 2016; accepted: $9 / 1 / 2017)$ 
REMOVAL OF SOME PHARMACEUTICALS AND ENDOCRINE DISRUPTING 155

تاثيربعض المركبات الصيدلانية و المركبات المعطلة للغدد الصماء على

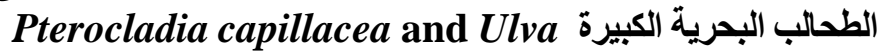

lactuca

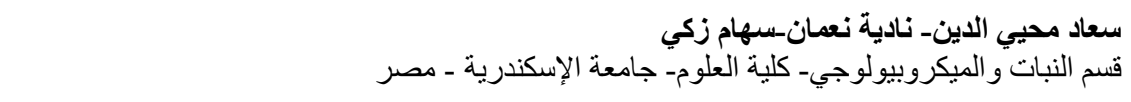

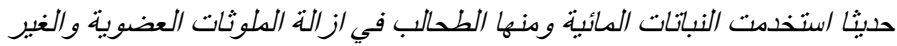

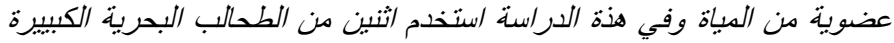

التيروكليديا والاولفا لفيا

في ازالة بعض المركبات الصيدلانية والمركبات المعطلة للغدد الصماء وهي

chloramphenicol, clofibric acid, acetyl salicylic acid, nonylphenol

and bisphenol

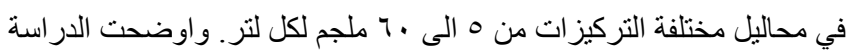

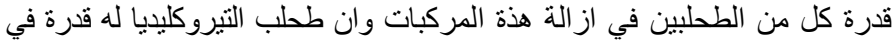

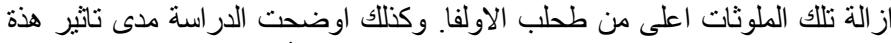

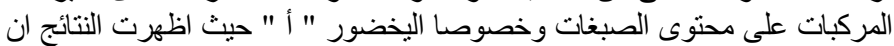

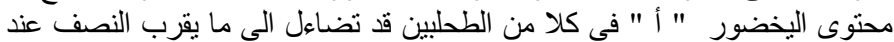

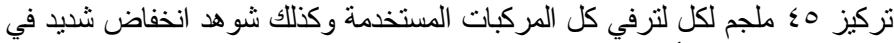

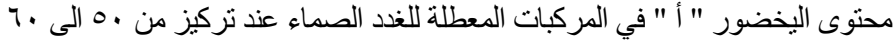

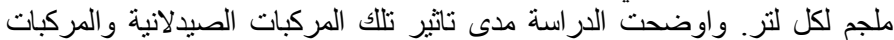

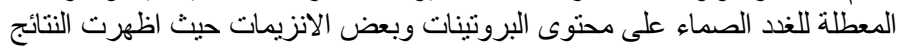

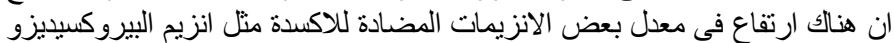

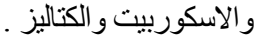

